\title{
Numerical and analytical study of seismic response of structural systems with new formulation using energy and impact methods
}

\author{
Mehdi Babaei $^{{ }^{*}}$, Somayeh Mollaei ${ }^{1}$, Amin Moslemi Petrudi ${ }^{2}$, Maysam Jalilkhani ${ }^{3}$, and \\ Ionut Cristian Scurtu $^{4}$ \\ ${ }^{1}$ Department of Civil Engineering, University of Bonab, East Azerbaijan, P. O. B. 45139-63391, P. O. \\ B. 55513-95133,Iran. \\ ${ }^{2}$ Department of Mechanical Engineering, IHU University, Tehran, P. O. B. 47155-66195, Iran \\ ${ }^{3}$ Department of Civil Engineering, Engineering Faculty of Khoy, Urmia University,P. O. B. 58159- \\ 14853, Iran. \\ ${ }^{4}$ Mircea cel Batran Naval Academy, Constanta, Romania
}

\begin{abstract}
This paper presents two simple and robust technique for response estimating of single-degree-of-freedom (SDOF) structural systems. The impulse method, because it is formulated based on the fundamentals of dynamics; especially, the linear impulse concept, and also the energy method, because the main idea of this method is inspired by energy conservation principles. These methods can strongly cope with linear damped systems for which damping ratio $\zeta$ is greater than 0.01.Assessment of SDOF dynamic systems under any arbitrary excitations is easily possible through the proposed methods. There is no error propagation through the solving process. The numerical example reveals the simplicity and robustness of the new technique compared to Duhamel's integral and similar techniques. Finally, a numerical example is investigated to demonstrate the efficiency of the algorithms. The most famous record of El Centro ground motion is applied to the systems. The obtained results show that the new algorithm works exactly enough to compete with a conventional method such as the Duhamel integration method and the Newmark- $\beta$ method.A comparison between the results of this method with the solution methods used by other researchers is shown to be a good match.
\end{abstract}

Keywords: Seismic response, SDOF system, Mass-spring oscillator, Impulse, and energy method. 


\section{Introduction}

The response of various dynamic systems, undergoing time-dependent changes, can be described by a second-order ordinary differential equation (ODE). As we know the merely linear differential equation can be analytically solved; and, there are numerous ODEs in applied mechanics, physics, biology, and economics for which analytical solutions are not achievable; especially, those that receive a noisy time-depending signal as input data. For this reason, the application of numerical techniques is indispensable for processing this family of ODEs. So, the numerical field of solving applied ODEs is one of the most active fields in science and engineering. Therefore, solving the governing equations of motion (EOM) for these systems would be of high importance for many applied problems. SDOF odel is the most known simplification of vibrating systems for seismic analysis of buildings and structures. Solving EOM of SDOF oscillators under base acceleration always have been a place of challenge for earthquake engineering researchers from the very early to the recent efforts [1]. Available methods to the solution of linear differential equations, such as EOM of SDOF systems, are mostly classical approaches like Duhamel's integral and frequency-domain method. In the classical solution, the response consists of the sum of the complementary solution and the particular solution. Duhamel's integral is based on representing the applied excitation as a sequence of infinitesimally short impulses. The frequency-domain method takes advantage of the Laplace and Fourier transforms. Besides, another category of numerical methods is known as stepwise methods. They are extended for analyzing nonlinear systems. The methods of excitation interpolation, central difference method, and also Newmark's method is the most commonly used numerical procedures in this family [2,3]. Accuracy of some numerical stepwise procedures used to compute the dynamic structural response of the SDOF system to a time-dependent excitation is evaluated in technical report ITL-97-7 published by the U.S. Army Corps of Engineers. They mainly investigated the Wilson- $\theta$ method, linear acceleration method, Newmark- $\beta$ algorithm, central difference method, the fourth-order Runge-Kutta method, and Duhamel's integral and Piecewise Exact Method [4]. Also, a new exact approach for forced vibration analysis of SDOF systems with arbitrary time-varying mass and stiffness was introduced by Li [5]. To conclude, most of the aforementioned conventional methods of solving SDOF's equation of motion, such as interpolation of excitation, Duhamel integral, central difference method, Wilson- $\theta$, and Newmark- $\beta$, have an insufficiently complex algorithm, offer a restricted level of precision, and almost difficult to understand techniques. Sometimes, they need advanced mathematical background and technical expertise. Most of the vibration cases in mechanics and structural engineering can be presented as an ideal single degree of freedom (SDOF) system (Paz \& Leigh, 2004). These systems follow an identical differential equation, the so-called equation of motion, which must be solved to identify its kinematic and kinetic parameters. Accordingly, solving differential equations of motion for vibrating systems is of great importance in mechanics and structural engineering. The solution of this equation can be a continuous analytical function or a numerical approximation computed at discrete time instances. Although analytical solutions are more desirable, there are merely some limited cases in applied mechanics that can be analytically solved by indeterminate integration; and, most of the real cases cannot be analytically solved. In these cases, for which indeterminate integration is not possible in its closed form, the implementation of numerical simulation is indispensable. In this regards, numerical solution of the equation of motion for the systems under irregularly changed excitation always has been a place of challenge for engineers from the very early studies $[6,7]$ up to the most recent ones [8-10]. Current approaches to the solution of linear differential equations are classified into two categories of numerical methods in mechanical systems. First, those which use the superposition principle in their formulation such as Duhamel 's integral and Fourier integral methods. These methods necessitate an evaluation of 
numerous response contributions at each time instance which is considered as a disadvantage with them. Besides, although these methods have theoretically strong formulation, none of them can be applied to nonlinear systems since nonlinear systems do not follow the superposition principle which is the basic assumption in their formulation. In this regard, numerous stepwise techniques have been coming into existence. Some of the most known stepwise methods are the piecewise exact method, finite difference method, integration-based methods. Integration based methods include a wide verity of techniques such as Euler-Gauss integration, Newmark- $\beta$ method, and Runge-Kutta integration [11-14]. Most of these method employs numerical approximation of integrals at each time step. There is a vast body of contribution in this field [15-20]. A similar issue is followed in this work to formulate new stepwise approaches. Chang tried to thoroughly confirm the performance of Newmark's method in solving nonlinear SDOF systems and its stability with numerical examples [21, 22]. Kazakov studied the dynamic response of the SDOF mass-spring system using Duhamel integral. They treated the problem as a form of Laplace integral transformation [23]. Also, a simple numerical method for computing the response of the SDOF system in terms of Taylor polynomials in the matrix form has been presented by Kurt and Çevik [24]. Li and Wu presented an iterative procedure to solve the nonlinear oscillations of a conservative SDOF system [25, 26]. Also, I introduced a new exact approach for forced vibration analysis of SDOF systems with arbitrary time-varying mass and stiffness [5].Mohsenian investigated the seismic reliability of diagrid structural systems and develop more efficient performance-based design methodologies. Demand and supply response modification factors are calculated for 16, 24, and 32-story buildings with diagrid structural systems using a $65^{\circ}$ diagrid angle and designed in compliance with current standards under a set of 12 spectrum compatible earthquakes [27]. Pang investigated to analyze the Magna earthquake sequence and resolve oblique-normal slip on a shallow (30$35^{\circ}$ ) west-dipping fault at $\sim 9$ - to $12-\mathrm{km}$ depth. Combined with near-surface geological observations of steep dip $\left(\sim 70^{\circ}\right)$, our results support a curved, or listric, fault shape. High-precision aftershock locations show the activation of multiple, low-angle $\left(<30-35^{\circ}\right)$ structures, indicating the existence of a complicated fault system [28]. Mitseas investigated an approximate stochastic dynamics technique for determining the system response amplitude probability density functions (PDFs) is developed. Firstly, relying on statistical linearization and state-variable formulation the complex eigenvalue problem is addressed through the time-domain [29]. Mitseas investigated a structural system comprising the bilinear hysteretic model serves as a numerical example for demonstrating the reliability of the proposed first-excursion PDF-based stochastic incremental dynamics methodology [30]. The merits of different stepwise methods originated from four main aspects: their convergence, level of precision, stability, and computational expense needed for a certain problem. However, having these advantages, most of the conventional methods have a sort of complicacy with their formulation, need high computational effort, and are sometimes difficult to understand. They need more or less advanced mathematical tools and technical expertise to use. Accordingly, we are to propose significantly easy techniques to deal with this problem. In this article, the simple energy method is introduced. It is motivated by the most known principle of energy conservation. This method introduced here is satisfactorily precise for analyzing linear damped system belonging viscous damping. They facilitate the assessment of SDOF response under any arbitrary irregular excitations and offer very simple platforms which makes it distinctive from its counterparts. Also, the simple method is introduced to solve the differential equation of vibrating SDOF systems. The initial idea of this method was initiated first by these authors working on an approximate solution of the merely mathematical differential equation [31]. However, the new method introduced here is highly precise and facilitates the assessment of SDOF dynamic response under any arbitrary excitations. The introduced procedure, the so-called impulse method, has a 
straightforward formulation based on the fundamentals of Dynamics, e.g., linear impulse concept. This method mainly targets SDOF linear damped systems undergoing earthquake excitation. The numerical example reveals the simplicity and efficiency of the impulse technique compared with the most known Duhamel's integral and Newmark- $\beta$ method. All computation is done by MATLAB software.

\section{Problem Statement}

Shown in Fig. 1 is the most known idealized linear mass-spring system. Commonly speaking, this system is composed of three main components: mass, spring, and damper.

As proved in the literature, if this system was under support movement of magnitude $a_{g}$ instead of external force $\mathrm{F}(\mathrm{t})$, the idealized system could be equalized as shown in Fig. 1. In this system, $-m a_{g}$ is substituted for the external force $\mathrm{F}(\mathrm{t})$, where $a_{g}$ denotes the acceleration of the system support and $x$ is the relative displacement of mass (or deformation of spring).

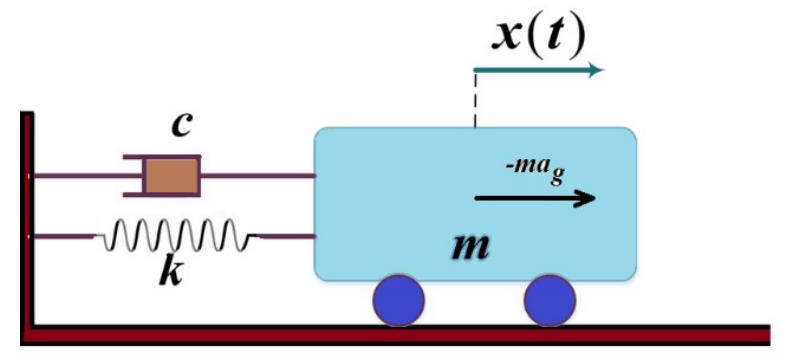

Fig.1 Idealized mass-spring model of vibration under support movement.

As proved in technical literature, denoting the displacement of mass by $x$ and its velocity and acceleration respectively by $v$ and $a$, and assuming linear behavior of spring, i.e., $F_{S}=k x$, and idealized viscously damping behavior of damper, i.e., $F_{D}=c v$, we can write the governing equation of motion $[2,14]$.

$$
k x+c v+m a=-m a_{g}
$$

Dividing equation (1) by mass $m$, the governing equation of motion for vibrating systems with linear components and undergoing ground acceleration is formulated as:

$$
\omega_{n}^{2} x+2 \zeta \omega_{n} v+a=-a_{g}
$$

where $\omega_{n}=\sqrt{\frac{k}{m}}$, is the natural frequency of the oscillating mass-spring system, $\zeta=\frac{c}{2 m \omega_{n}}$ is the damping ratio, and $a_{g}(t)$ is the ground (or support) acceleration. This equation indicates that any two systems with the same natural frequency and damping ratio have identicalresponse $x(t)$, regardless of being massive and stiffer relative to each other. This equation is an alternative expression of the vibration equation that we may use in our formulation.

\section{Methodology: Proposed Impulse Method}

To propose an easily employable technique for dealing with the most known vibration problem, i.e., damping SDOFsystems, we first recall the concept of impulse in mechanics. The product of force and time is defined as the linear impulse of the force: 


$$
d I=F d t
$$

And the total impulse of the mass $m$ from time instance $t_{i}$ to $t_{i+1}$ is indicated as:

$$
I=\int_{t_{i}}^{t_{i+1}} F d t
$$

Multiplying Eq. (1) by time differential, $d t$, we have:

$$
k x d t+c v d t+m a d t=-m a_{g} d t
$$

It means that the differential impulse of the system in dynamic equilibrium is conservative during a time differential $d t$. Recalling that $v=d x / d t$ and $a=d v / d t$ we have:

$$
k x d t+c \frac{d x}{d t} d t+m \frac{d v}{d t} d t=-m a_{g} d t
$$

Integrating Eq. (6) from $t_{i}$ to $t_{i+1}$ gives:

$$
\begin{array}{r}
\int_{t_{i}}^{t_{i+1}} k x d t+\int_{x_{i}}^{x_{i+1}} c d x+\int_{v_{i}}^{v_{i+1}} \operatorname{madt} \\
=\int_{t_{i}}^{t_{i+1}}-m a_{g} d t
\end{array}
$$

Assuming linear variation for components $x$ and $a_{g}$ and employing a trapezoidal integration method, we have:

$$
\begin{aligned}
\frac{k \Delta t}{2}\left(x_{i+1}+x_{i}\right)+c\left(x_{i+1}\right. & \left.-x_{i}\right)+\frac{m \Delta t}{2}\left(a_{i+1}+a_{i}\right) \\
& =-\frac{m \Delta t}{2}\left(a_{g . i+1}+a_{g . i}\right)
\end{aligned}
$$

Each term of this equation is the total impulse of a force component of SDOF as well as spring force, friction force, inertia force, and the force from external excitation. It means that the resultant impulse of component forces is conservative during the time step from $t_{i}$ to $t_{i+1}$. This formula gives the recursive relationship needed to compute $x_{i+1}, v_{i+1}$ during a time step. For this purpose, we rewrite the equation (8) as:

$$
\begin{aligned}
x_{i+1} & =x_{i}+\left[-\frac{m \Delta t}{2}\left[\left(a_{g . i}+a_{g . i+1}\right)\right.\right. \\
+ & \omega_{n}^{2}\left(x_{i}+x_{i+1}\right) \\
+ & \left.\left.\left(a_{i}+a_{i+1}\right)\right]\right] / c \\
v_{i+1} & =v_{i}+\left[-\frac{m \Delta t}{2}\left[\left(a_{g . i}+a_{g . i+1}\right)\right.\right. \\
+ & \omega_{n}^{2}\left(x_{i}+x_{i+1}\right) \\
+ & \left.\left.2 \omega_{n} \zeta\left(v_{i}+v_{i+1}\right)\right]\right] / m
\end{aligned}
$$

Where $\omega_{n}^{2}=k / m$ and $2 \omega_{n} \zeta=c / m . \omega_{n}$ and $\zeta$ are respectively natural frequency and damping coefficient of the system. Simplifing Eq.s (9) and (10) respectively, we obtain: 


$$
\begin{array}{r}
x_{i+1}=x_{i}-\frac{m \Delta t}{2 \mathrm{c}}\left[\left(a_{g . i}+a_{g . i+1}\right)\right. \\
\left.+\omega_{n}^{2}\left(x_{i}+x_{i+1}\right)+\left(a_{i}+a_{i+1}\right)\right] \\
v_{i+1}=v_{i}-\frac{\Delta t}{2}\left[\left(a_{g . i}+a_{g . i+1}\right)+\omega_{n}^{2}\left(x_{i}+x_{i+1}\right)\right. \\
\left.+2 \omega_{n} \zeta\left(v_{i}+v_{i+1}\right)\right]
\end{array}
$$

Finally, we must compute and update the magnitude of the acceleration $a_{i+1}$ while updating $x_{i+1}$ and $v_{i+1}$ Acceleration response of any SDOF systems has very important information on system state and it contains high details of the mass movements in the dynamic system. Therefore, the iterative process isseverely sensitive to its value and if itwas not accurate enough, the iteration process would rapidly diverge. This is a key point while using the impulse technique. At any instance, we compute acceleration by the differential equations of motion (DEM) of the system:

$$
a_{i+1}=-\left(a_{g . i+1}+\omega_{n}^{2} x_{i+1}+2 \omega_{n} \zeta v_{i+1}\right)
$$

These relations constitute the trunk of the impulse technique algorithm.

Now, the question isthat "what are the values of $x_{i+1}, v_{i+1}$, while we initialize to calculate $x_{i+1}, v_{i+1}$ themselves? " To answerthis question, we note that the variation of geometricparameters of motion $x$ and $v$ is almost infinitesimal during a time step. So, we can start each instance computation, assuming that $x_{i+1}, v_{i+1}$ are both equal to $x_{i}, v_{i}$, respectively. The step-by-step process of the suggested method is summarized in Table 1.

Table 1 Step-by-step algorithm of the proposed impulse method.

1. For time instance $i=1$ initialize with *

$t_{1}=0 . \quad x_{1}=x(0) . v_{1}=v(0) . a_{1}$

$$
=-\left(a_{g .1}+\omega_{n}^{2} x_{1}+2 \omega_{n} \zeta v_{1}\right)
$$

2. Predict the response at instance $i+1$

$$
x_{i+1}=x_{i}+\frac{\Delta t}{2} v_{i}, v_{i+1}=v_{i}+\frac{\Delta t}{2} a_{i}
$$

3. Update $x_{i+1}, v_{i+1}, a_{i+1}$ :

$$
\begin{gathered}
a_{i+1}=-\left(a_{g . i+1}+\omega_{n}^{2} x_{i+1}+2 \omega_{n} \zeta v_{i+1}\right) \\
\begin{aligned}
x_{i+1}=x_{i}-\frac{m \Delta t}{2 \mathrm{c}} & {\left[\left(a_{g . i}+a_{g . i+1}\right)+\omega_{n}^{2}\left(x_{i}+x_{i+1}\right)\right.} \\
& \left.+\left(a_{i}+a_{i+1}\right)\right] \\
v_{i+1}=v_{i}-\frac{\Delta t}{2}[ & \left(a_{g . i}+a_{g . i+1}\right)+\omega_{n}^{2}\left(x_{i}+x_{i+1}\right) \\
& +2 \omega_{n} \zeta\left(v_{i}+v_{i+1}\right)
\end{aligned}
\end{gathered}
$$

4. Repeat steps 3 and 4 until desirable precision is achieved.

5. Set $i=i+1$ and repeat steps 2 to 5 for the next time instance. 


$$
\begin{gathered}
\text { *For the case of external loads instead, use the } \\
\text { followings in steps } 1 \text { and } 3 \text {, respectively } \\
a_{1}=\left[F_{1}-\left(k x_{1}+c v_{1}\right)\right] / m \quad, \quad a_{i+1}=\left[F_{i+1}-\right. \\
\left.\left(k x_{i+1}+c v_{i+1}\right)\right] / m
\end{gathered}
$$

Despite the extraordinary simplicity of this algorithm, it works accurately for damped linear systems. This is investigated through a numerical example under earthquake records. It should be noted that the current version of the impulse method is merely applicable to linear systems for which the damping ratio $\zeta$ is at least greater than 0.01 .

There is a clear criterion to test any numerical solution presented for vibration differential equations. If the solution was exact, the unbalanced force diminishes. Denoting the force by the residual of the differential equation we have:

$$
\operatorname{Res}(t)=k x(t)+c v(t)+m a(t)+m a_{g}
$$

Accordingly, for the numerical solution which is presented at discrete points of time, the value of this function can be the best tool for precision judgment. So, we introduce the absolute value of the error function to check the exactness of oursolutions:

$$
\operatorname{ErrFun}\left(t_{i}\right)=\left|k x_{i}+c v_{i}+m a_{i}+m a_{g i}\right|
$$

If the value of the error function vanishes, the appropriately precise solution is found.

\section{Methodology: Proposed Energy Method}

The first recall the definition of the work done by a force during the straight pass $d x$ :

$$
d U=F d x
$$

Then, multiplying Eq. (1) by $d x$ we have:

$$
k x d x+c v d x+m a d x=-m a_{g} d x
$$

Each term of thisequation can be interpreted as the work or energy induced by its corresponding force component. It means, $k x d x$ is the differential energy of spring, $c v d x$ is the differential energy dissipated by friction force, $m a d x$ is the differential kinetic energy of the system, and $-m a_{g} d x$ can be considered as the differential work done by ground acceleration which is the mere agent of motion. Eq. (17) means that energy income from earthquake force is distributed among the three essential components of the system, i.e., spring, friction, and inertia. Now, to reform this equation some technical modification is conducted. Recalling $v=\frac{d x}{d t}$ and $a_{g}=\frac{d v_{g}}{d t}$ and substituting them into Eq. (17),we have: $k x d x+c v d x+\operatorname{mad} x=-m v d v_{g}$

Dividing the last equation by $v$ and noting that $\frac{d x}{v}=d t$, we can Integrate Eq. (18) from $i$ to $i+1$ :

$$
\begin{aligned}
& \int_{t_{i}}^{t_{i+1}} k x d t+\int_{x_{i}}^{x_{i+1}} c d x+\int_{t_{i}}^{t_{i+1}} \operatorname{madt} \\
& =\int_{v_{g . i}}^{v_{g . i+1}}-m d v_{g}
\end{aligned}
$$


Then:

$$
\begin{aligned}
& \frac{k \Delta t}{2}\left(x_{i}+x_{i+1}\right)+c\left(x_{i+1}-x_{i}\right)+\frac{m \Delta t}{2}\left(a_{i}+a_{i+1}\right) \\
= & -m\left(v_{g . i+1}-v_{g . i}\right)
\end{aligned}
$$

Solving the last equation for $x_{i+1}$ :

$$
\begin{aligned}
x_{i+1}= & -\left[m\left(v_{g . i+1}-v_{g . i}\right)+\left(\frac{k \Delta t}{2}-c\right) x_{i}\right. \\
& \left.+\frac{m \Delta t}{2}\left(a_{i}+a_{i+1}\right)\right] /\left(\frac{k \Delta t}{2}+c\right)
\end{aligned}
$$

This gives the recursive relationship for $x_{i+1}$. Similarly, the following can be obtained for velocity:

$$
\begin{gathered}
v_{i+1}=v_{i}- \\
{\left[m\left(v_{g . i+1}-v_{g . i}\right)+\left(\frac{k \Delta t}{2}-c\right) x_{i}+\left(\frac{k \Delta t}{2}\right.\right.} \\
\left.+c) x_{i+1}\right] / m
\end{gathered}
$$

Eq. (21) and (22)coupledwith the following relation obtained:

$\ddot{x}_{i+1}=-\left(a_{g . i+1}+\omega_{n}^{2} x_{i+1}+2 \omega_{n} \zeta v_{i+1}\right)$

constitute the numerical algorithm for computing linear SDOF response. The algorithm of the energy approach is summarized in Table 2. Despite the extreme simplicity with energy methods, it works precisely for linear damped systems.

Table 2 Step-by-step algorithm of the proposede nergy method.

1. For time instance $i=1$ initialize with *

$$
t_{1}=0 . x_{1}=x(0) \cdot v_{1}=v(0) \cdot a_{1}=-\left(a_{g .1}+\omega_{n}^{2} x_{1}+2 \omega_{n} \zeta v_{1}\right)
$$

2. Predict the response at instance $i+1$

$x_{i+1}=x_{i}+\Delta t v_{i}, v_{i+1}=v_{i}+\Delta t a_{i}$

3. Correct the system state using the following

$\ddot{x}_{i+1}=-\left(a_{g . i+1}+\omega_{n}^{2} x_{i+1}+2 \omega_{n} \zeta v_{i+1}\right)$

$x_{i+1}=-\left[m\left(v_{g . i+1}-v_{g . i}\right)+\left(\frac{k \Delta t}{2}-c\right) x_{i}+\frac{m \Delta t}{2}\left(a_{i}+a_{i+1}\right)\right] /\left(\frac{k \Delta t}{2}+c\right)$

$\dot{x}_{i+1}=v_{i}-\left[m\left(v_{g . i+1}-v_{g . i}\right)+\left(\frac{k \Delta t}{2}-c\right) x_{i}+\left(\frac{k \Delta t}{2}+c\right) x_{i+1}\right] / m$

4. Repeat step 3 and 4 until desirable precision

5. Set $i=i+1$ and repeat steps 2 to 5 for the next time instance.

*For the case of external loads instead, use the followings in steps 1 and 3, respectively 
$\ddot{x}_{1}=\left[F_{1}-\left(k x_{1}+c v_{1}\right)\right] / m \quad, \quad \ddot{x}_{i+1}=\left[F_{i+1}-\left(k x_{i+1}+c v_{i+1}\right)\right] / m$

Important note:The load impulse method does not yield reliable results for undamped systems and the system with $\zeta \leq 0.01$. In these cases, the integration method is advised which will be presented in the next sections. However, most of the applied cases have a damping ratio greaterthan 0.01 , i.e., $(\zeta \geq 0.01)$.

\section{Result and discussion}

\subsection{The linear damped system under El Centro's earthquake}

A general case of the dynamiclinear system underearthquake excitation is investigated. The system to be investigated is a linear damped system:

Mass: $m=1 \mathrm{~kg}$

Natural period: $T_{n}=0.5 \mathrm{sec}$

Damping ratio: $\zeta=0.02$

Timestep of the ground motion record: $\Delta t=0.02 \mathrm{sec}$

Peak ground acceleration of the ground motion:PGA $=0.31882 \mathrm{~g}=0.31882 \times$ $386.22=123.134 \mathrm{in} \mathrm{sec}^{2}$

Natural angular frequency:

$$
\omega_{n}=2 \pi / T_{n}=2 \times 3.1415 / 0.5=12.5663 \mathrm{rad} / \mathrm{sec}
$$

Spring constant:

$$
k=m \omega_{n}^{2}=1 \times 12.562^{2}=157.9 \mathrm{kip} / \mathrm{in}
$$

Damping coefficient:

$$
c=2 m \omega_{n} \zeta=2 \times 1 \times 12.56 \times 0.02=0.5027
$$

El Centro's ground acceleration (Fig. 2) is applied to the system which was initially at rest.

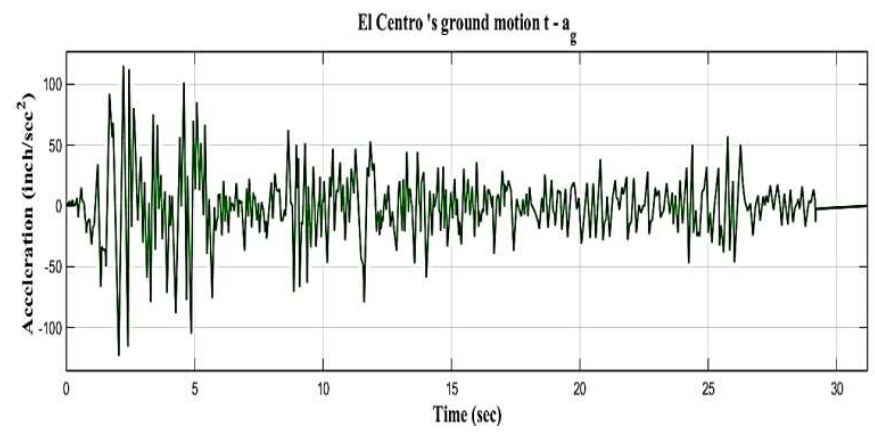

Fig. 2 El Centro's ground motion.

The dynamic response of the system is obtained by the energy method. Then, to have a comparison with conventional methods, the dynamic response of the system is also 
computed with Duhamel integral and Newmark- $\beta$ method. All responses are presented in Fig. 3. All methods yield approximately close responses.

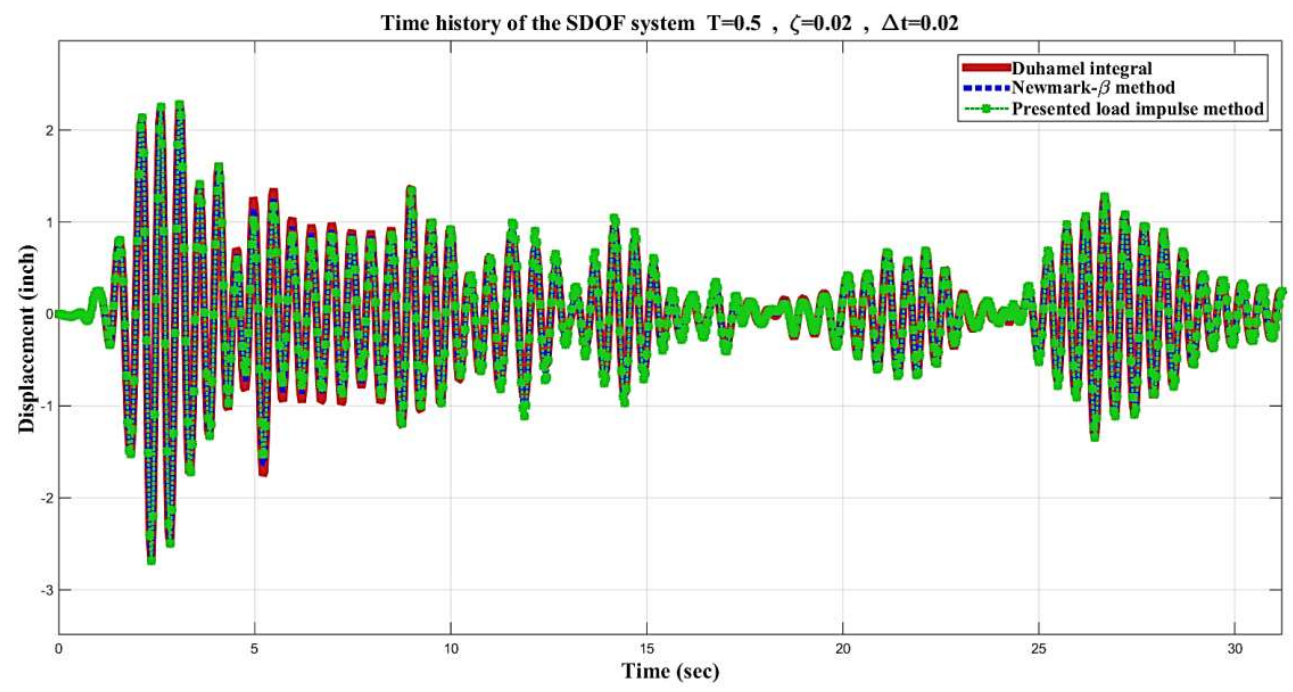

a)

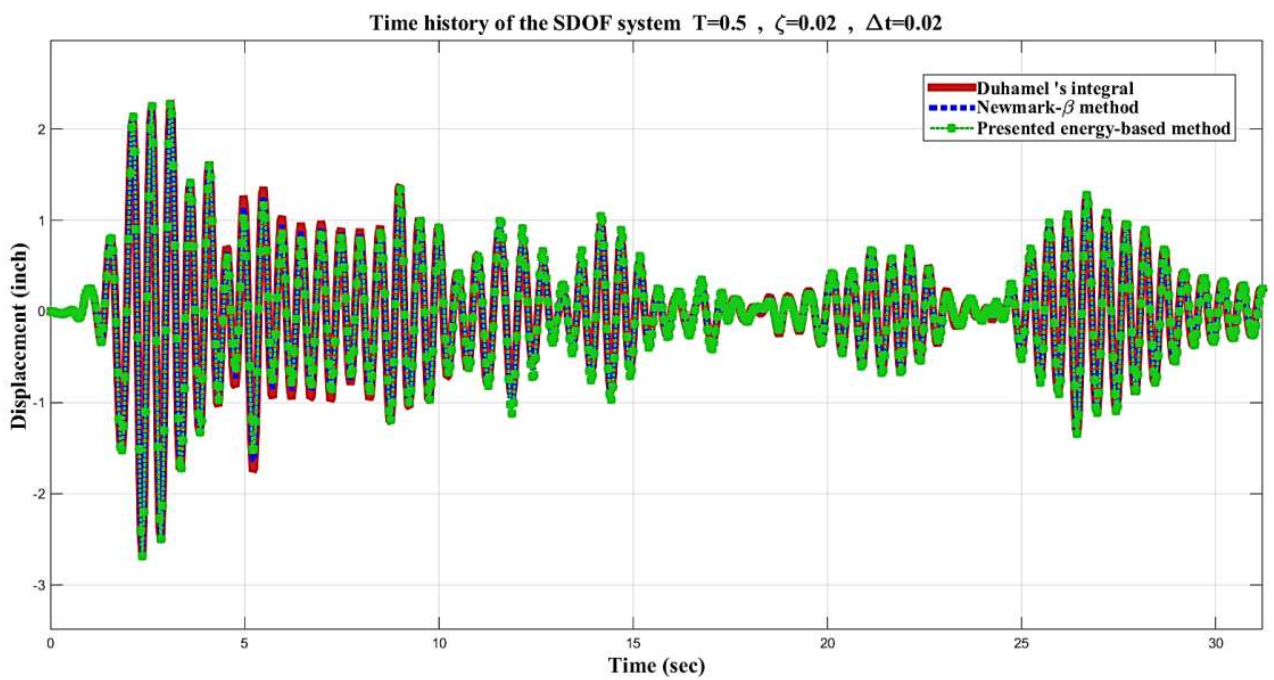

b)

Fig. 3 Response of the linear SDOF system to the El Centro earthquake.

Fig. 3 indicates that the new methods can properly detect the motion even with normal time increment. Moreover, it is observed that any appeared errors at the peak points of responses do not propagate to the proceeding steps; and, errors decay after some limited number of cycles.Numerical results are summarized in Table 2 to transmit a clear insight into solution precision. Duhamel's integral works more precisely than the others; however, it uses computation of order $[\mathrm{O}]^{2}$ which would be very costly for the smaller time step size. 
Table 3 Summary results for the response of the linear SDOF system to the El Centro earthquake $(\Delta t=0.02 \mathrm{sec})$.

\begin{tabular}{|c|c|c|c|c|}
\hline $\begin{array}{c}\text { Time } \\
\text { instance } \\
\boldsymbol{t}_{\boldsymbol{i}}(\mathrm{sec})\end{array}$ & $\begin{array}{l}\text { Duhamel } \\
\text { 's } \\
\text { integral } \\
x_{\boldsymbol{i}} \text { (inch) } \\
\end{array}$ & $\begin{array}{l}\text { Newmark- } \\
\beta \text { method } \\
\boldsymbol{x}_{\boldsymbol{i}} \text { (inch) }\end{array}$ & $\begin{array}{c}\text { Energy } \\
\text { method } \\
\boldsymbol{x}_{\boldsymbol{i}} \\
\text { (inch) } \\
\end{array}$ & $\begin{array}{c}\text { Impulse } \\
\text { method } \\
\boldsymbol{x}_{\boldsymbol{i}} \\
\text { (inch) } \\
\end{array}$ \\
\hline 0 & 0.0000 & 0.0000 & 0.0000 & 0.0000 \\
\hline 0.8 & -0.0100 & -0.0094 & $\begin{array}{c}- \\
0.0092\end{array}$ & -0.0092 \\
\hline 1.6 & 0.6602 & 0.6627 & 0.6650 & 0.6650 \\
\hline 2.4 & -2.1659 & -2.1811 & $\begin{array}{c}- \\
2.1975\end{array}$ & -2.1975 \\
\hline 3.2 & 0.5313 & 0.6260 & 0.7177 & 0.7175 \\
\hline 4 & 0.9774 & 0.8689 & 0.7553 & 0.7556 \\
\hline 4.8 & -0.6248 & -0.5776 & $\begin{array}{c}- \\
0.5164\end{array}$ & -0.5166 \\
\hline 5.6 & 0.0624 & 0.1226 & 0.1619 & 0.1618 \\
\hline 6.4 & 0.8159 & 0.7155 & 0.6275 & 0.6277 \\
\hline 7.2 & -0.9830 & -0.9046 & $\begin{array}{c}- \\
0.8240\end{array}$ & -0.8241 \\
\hline 8 & 0.7710 & 0.7535 & 0.7198 & 0.7198 \\
\hline 8.8 & -0.9259 & -0.9730 & $\begin{array}{c}- \\
0.9976\end{array}$ & -0.9976 \\
\hline 9.6 & 0.2967 & 0.3937 & 0.4739 & 0.4737 \\
\hline 10.4 & 0.2663 & 0.1632 & 0.0639 & 0.0641 \\
\hline 11.2 & -0.7026 & -0.6424 & $\begin{array}{c}- \\
0.5687 \\
\end{array}$ & -0.5689 \\
\hline 12 & -0.2292 & -0.2397 & $\begin{array}{c}- \\
0.2727 \\
\end{array}$ & -0.2726 \\
\hline 12.8 & 0.1215 & 0.1003 & 0.1018 & 0.1018 \\
\hline 13.6 & 0.2956 & 0.3357 & 0.3594 & 0.3594 \\
\hline 14.4 & -0.8320 & -0.8687 & $\begin{array}{c}- \\
0.9000\end{array}$ & -0.8999 \\
\hline 15.2 & 0.4913 & 0.5338 & 0.5806 & 0.5805 \\
\hline 16 & 0.0490 & 0.0026 & $\begin{array}{c}- \\
0.0548 \\
\end{array}$ & -0.0547 \\
\hline 16.8 & 0.2190 & 0.2451 & 0.2868 & 0.2867 \\
\hline 17.6 & 0.1503 & 0.1396 & 0.1144 & 0.1144 \\
\hline 18.4 & 0.0520 & 0.0436 & 0.0450 & 0.0450 \\
\hline 19.2 & -0.1290 & -0.1076 & $\begin{array}{c}- \\
0.0894\end{array}$ & -0.0895 \\
\hline 20 & 0.1717 & 0.1483 & 0.1215 & 0.1216 \\
\hline 20.8 & -0.2613 & -0.2425 & $\begin{array}{c}- \\
0.2142 \\
\end{array}$ & -0.2143 \\
\hline 21.6 & 0.4351 & 0.4219 & 0.3980 & 0.3981 \\
\hline 22.4 & -0.5252 & -0.5362 & $\begin{array}{c}- \\
0.5362 \\
\end{array}$ & -0.5362 \\
\hline 23.2 & -0.0088 & 0.0315 & 0.0643 & 0.0642 \\
\hline 24 & -0.0193 & -0.0590 & $\begin{array}{c}- \\
0.0988\end{array}$ & -0.0987 \\
\hline
\end{tabular}




\begin{tabular}{|c|c|c|c|c|}
\hline 24.8 & 0.1708 & 0.1959 & 0.2277 & 0.2276 \\
\hline 25.6 & 0.0734 & 0.0516 & 0.0188 & 0.0189 \\
\hline 26.4 & -1.2889 & -1.2637 & - & -1.2266 \\
& & & 1.2265 & \\
\hline 27.2 & 1.0664 & 1.0781 & 1.0772 & 1.0772 \\
\hline 28 & -0.5742 & -0.6338 & - & -0.6835 \\
& & & 0.6836 & \\
\hline 28.8 & 0.0001 & 0.0877 & 0.1733 & 0.1731 \\
\hline 29.6 & 0.2521 & 0.1807 & 0.1000 & 0.1002 \\
\hline 30.4 & -0.2948 & -0.2638 & - & -0.2153 \\
& & & 0.2152 & \\
\hline 31.2 & 0.2382 & 0.2518 & 0.2457 & 0.2457 \\
\hline
\end{tabular}

The peak of displacement, velocity, and accelerationisalsopresented in Table 3. This information istakenfrom the responses of time increment $\Delta t=0.002 \mathrm{sec}$. A notable piece of information in this table is the measured run time corresponding to each method. The results show that Duhamel integralis the slowestalgorithmwhichneeds high computationalcost and the Newmark- $\beta$ methodis the fastest of all.

Table 4 Peak values of responses of various methods with a time increment of $\Delta t=0.002 \mathrm{sec}$.

\begin{tabular}{|l|c|c|c|c|}
\hline \multicolumn{1}{|c|}{ Item } & $\begin{array}{c}\text { Duhamel's } \\
\text { integral }\end{array}$ & $\begin{array}{c}\text { Newmark- } \\
\beta \text { method }\end{array}$ & $\begin{array}{c}\text { Energy } \\
\text { method }\end{array}$ & $\begin{array}{c}\text { Impulse } \\
\text { method }\end{array}$ \\
\hline $\begin{array}{l}\text { Max Disp. } \\
\text { (inch) }\end{array}$ & 2.6881 & 2.6879 & 2.7033 & 2.6879 \\
\hline $\begin{array}{l}\text { Max Vel. } \\
\text { (inch/sec) }\end{array}$ & $\mathrm{NC}^{*}$ & 32.2654 & 32.4484 & 32.2633 \\
\hline $\begin{array}{l}\text { Max } \\
\text { Acceleration } \\
\text { (inch/sec }\end{array}$ ) & $\mathrm{NC}^{*}$ & 486.421 & 487.678 & 486.421 \\
\hline $\begin{array}{l}\text { Number of } \\
\text { iteration }\end{array}$ & 1 & 1 & 5 & 3 \\
\hline $\begin{array}{l}\text { Analyses } \\
\text { time (sec) }\end{array}$ & 13.015 & 0.0019 & 0.0130 & 0.0083 \\
\hline
\end{tabular}

*NC: Not computed

\section{Conclusions}

In this study, a simple numerical formulation, the Impulse, and energy method were proposed to obtain the dynamic response of linear damped SDOF systems under the seismic loading. Results show that the proposed procedures satisfactorily estimate the seismic response of the linear damped SDOF systems. Another noticeable observation is that the estimation errors from the methods are not accumulated in each analysis step and gradually decreased while analysis proceeds. It can be concluded from the results; the load impulse algorithm can reliably estimate the displacement. There was good agreement between the resultsfrom the impulse method and that one time-history of the SDOF systems from Duhamel integral and Newmark- $\beta$ methods. Accordingly, the proposed method can be identified as a reliable analysis tool in estimating the seismic demand for linear damped SDOF systems. Further studies in the development of the proposed procedure for 
estimating the seismic response of other types of structural systems such as inelastic nonlinear SDOF models are still underway.

The energy conservation principle trigger edits base idea. It is employed to manipulate the original form of the vibration equation in a differential form. Then, the differential terms of the equation are manipulated by kinematic relations of motion to reform the configuration of the equation.

The most important characteristics of the presented methods can be summarized as:

1) Computer programming is very simple for both methods.

2) Current models are simple iterative calculation.

3) Any arbitrary type of excitation such as harmonic, impulse, and even irregular earthquake excitation can be treated.

4) Advanced mathematical tools are avoided and computational operations are composed of very basic operations.

5) Analyzing a linear SDOF system is accessible even with beginners in earthquake engineering.

6) Any appeared errors, regardless of their sources, do not propagate proceeding steps.

7) They have low computation cost in comparison with Duhamel integral.

and limitations with the proposed methods are:

1) It is formulated merely for linear systems; and, they cannot deal with nonlinear systems.

2) it cannot converge for undamped systems and those for which $\zeta<0.01$.

3) Convergence speed is dissatisfying with this algorithm.

The performance of the methods is checked through a general numerous example. Mathematical discussion on the stability of the new algorithmis not included in current research; however, convergence and stability of solution are evident in example diagrams. Further development of energy methods for dealing with nonlinear structural systems is still underway.

\section{References}

1. Izadifard, R.A., Mollaei, S. and Omran, M.E.N. "Preparing pressure-impulse diagrams for reinforced concrete columns with constant axial load using single degree of freedom approach", International Journal of Advancements in Technology, 2016.

2. https://doi.org/10.4172/0976-4860.1000173

3. Bathe, K.J."Frontiers in finite element procedures". Klaus-Jurgen Bathe, 2006.https://doi.org/10.4203/csets.35.1

4. Chopra, A.K."Dynamics of structures", (pp. 174-196). Upper Saddle River, NJ: Pearson Education, 2012.

5. Ebeling, Robert M., Russell A. Green, and Samuel E. French. "Accuracy of response of single-degree-of-freedom systems to ground motion",Army Corps of Engineers, 97-7, 1997.

6. https://doi.org/10.21236/ada336674

7. Li, P.S. and $\mathrm{Wu}$, B.S."An iteration approach to nonlinear oscillations of conservative single-degree-of-freedom systems", Acta Mechanica, 170(1-2), pp.69-75, 2004.

8. https://doi.org/10.1007/s00707-004-0112-3 
9. Newmark, N.M."A method of computation for structural dynamics", Journal of the engineering mechanics division, 85(3), pp.67-94, 1959.

10. Veletsos, A.S., Newmark, N.M. and Chelapati, C.V. January. "Deformation spectra for elastic and elastoplastic systems subjected to ground shock and earthquake motions", In Proceedings of the 3rd world conference on earthquake engineering (Vol. 2, pp. 663-682), 1965.

11. Wang, Y. and Inman, D.J."Autonomous Gust Alleviation in UAVs", Advanced UAV Aerodynamics, Flight Stability and Control: Novel Concepts, Theory and Applications, p.465, 2017.

12. https://doi.org/10.1002/9781118928691

13. Gawronski, W."Advanced structural dynamics and active control of structures", Springer Science \& Business Media, 2004.

14. https://doi.org/10.1007/978-0-387-72133-0

15. Benaroya, H., Nagurka, M. and Han, S."Mechanical vibration: analysis, uncertainties, and control", CRC Press, 2017.

16. https://doi.org/10.1201/9781315118369

17. Paz, M."International handbook of earthquake engineering: codes, programs, and examples", Springer Science \& Business Media, 2012.

18. https://doi.org/10.1007/978-1-4615-2069-6

19. Wu, B. S., \& Lim, C. W. "Large amplitude non-linear oscillations of a general conservative system", International Journal of Non-Linear Mechanics, 39(5), 859870, 2004.

20. https://doi.org/10.1016/S0020-7462(03)00071-4

21. Chopra, A. K., Goel, R. K., \& Chintanapakdee, C. "Statistics of single-degree-offreedom estimate of displacement for pushover analysis of buildings", Journal of structural engineering, 129(4), 459-469, 2003.

22. https://doi.org/10.1061/(ASCE)0733-9445(2003)129:4(459)

23. Clough, R.W. and Penzien, J. "Dynamics of Structures (3rd)", Computers \& Structures, Inc., California, pp.342-344, 2003.

24. https://doi.org/10.1115/1.3424082

25. Craig, R. R., \&Kurdila, A. J. "Fundamentals of structural dynamics", John Wiley \& Sons, 2006.

26. Gatti, P. L. "Applied Structural and Mechanical Vibrations: Theory and Methods". CRC Press, 2014.

27. https://doi.org/10.1201/b16697

28. Géradin, M., \&Rixen, D. J. "Mechanical vibrations: theory and application to structural dynamics". John Wiley \& Sons, 2014.

29. Anderson, J.C. and Naeim, F. "Basic structural dynamics", John Wiley \& Sons, 2012.

30. https://doi.org/10.1002/9781118279137

31. Paz, M. and Leigh, W. "Structural Dynamics: Theory and Computation, 5th Ed", Springer Science \& Business Media, N.Y, 2004. https://doi.org/10.1007/978-14615-0481-8

32. Rao, S. S."Mechanical vibrations in SI units", Pearson Higher Ed, 2017.

33. Chang, S.Y."Studies of Newmark method for solving nonlinear systems:(I) basic analysis", Journal of the Chinese Institute of Engineers, 27(5), pp.651-662, 2004.

34. https://doi.org/10.1080/02533839.2004.9670913 
35. Chang, S.Y."Studies of Newmark method for solving nonlinear systems:(II) Verification and guideline", Journal of the Chinese institute of engineers, 27(5), pp.663-675, 2004.

36. https://doi.org/10.1080/02533839.2004.9670914

37. Kazakov, K. S."Dynamic Response of a Single Degree of Freedom (SDOF) System in some Special Load Cases, based on the Duhamel Integral", In International Conference on Engineering Optimization (pp. 01-05), 2008.

38. Kurt, N., \&Çevik, M. "Polynomial solution of the single degree of freedom system by Taylor matrix method", Mechanics Research Communications, 35(8), 530-536, 2008.

39. $\mathrm{Wu}$, J. S. "Analytical and numerical methods for vibration analyses", John Wiley \& Sons, 2013.

40. Thomson, W. "Theory of vibration with applications", CrC Press, 2018.

41. Mohsenian, V., Padashpour, S. and Hajirasouliha, I. "Seismic reliability analysis and estimation of multilevel response modification factor for steel diagrid structural systems", Journal of Building Engineering, 29, p.101168, 2020.

42. https://doi.org/10.1016/j.jobe.2019.101168

43. Pang, G., Koper, K.D., Mesimeri, M., Pankow, K.L., Baker, B., Farrell, J., Holt, J. "Seismic analysis of the 2020 Magna, Utah, earthquake sequence: Evidence for a listric Wasatch fault", Geophysical Research Letters, 47(18), p. e2020GL089798, 2020. https://doi.org/10.1029/2020GL08979

44. Mitseas, I.P. and Beer, M., 2020. "Fragility analysis of nonproportionally damped inelastic MDOF structural systems exposed to stochastic seismic excitation", Computers \& Structures, 226, p.106129.

45. https://doi.org/10.1016/j.compstruc.2019.106129

46. Mitseas, I.P. and Beer, M., 2020. "First-excursion stochastic incremental dynamics methodology for hysteretic structural systems subject to seismic excitation", Computers \& Structures, 242, p.106359.

47. https://doi.org/10.1016/j.compstruc.2020.106359

48. Babaei, M."A general approach to approximate solutions of nonlinear differential equations using particle swarm optimization", Applied Soft Computing, 13(7), pp.3354-3365, 2013. https://doi.org/10.1016/j.asoc.2013.02.005

49. [31] Rahmani , M., Scurtu, I. C., \& Moslemi Petrudi, A. (2020). Analytical and Dynamic study of Pulled Mass Nonlinear Vibration by Two Cables using Newton's Harmonic Balance Method. Technium: Romanian Journal of Applied Sciences and Technology, 2(2), 79-86. https://doi.org/10.47577/technium.v2i2.343 